\title{
ROLE OF ROUTINE SCREENING IMAGING MODALITIES IN THE DIAGNOSIS OF SITUS INVERSUS TOTALIS- OUR EXPERIENCE
}

\author{
Ashok Kumar Mandal' ${ }^{1}$ Abhijit Bhowmik ${ }^{2}$ \\ 1 Professor, Department of Radiodiagnosis, Patna Medical College and Hospital. \\ 2Junior Resident, Department of Radiodiagnosis, Patna Medical College and Hospital.
}

\begin{abstract}
BACKGROUND

Situs inversus totalis is rare with incidence of one in ten thousand. It is usually associated with dextrocardia (true mirror image) with only $3 \%-5 \%$ incidence of congenital heart disease, the most common being transposition of the great vessels. However, surgeons, radiologists and general practitioners should be aware of this condition as it may lead to wrong diagnosis and surgical mishaps.
\end{abstract}

\section{MATERIALS AND METHODS}

In this study, we have included the patients who were diagnosed with dextrocardia on routine chest x-ray over a 5-year period from March 2012 to February 2017. We studied the imaging findings using routine screening imaging modalities like transabdominal ultrasound together with computed tomography, barium studies where applicable in the diagnosis of this relatively rare condition. The electrocardiogram findings were also assessed.

\section{RESULTS}

We encountered 45 cases of dextrocardia during the 5-year period. Transabdominal ultrasound revealed transposition of liver, gall bladder, spleen, stomach and abdominal blood vessels. Computed tomography and barium studies reinforced the diagnosis. Electrocardiogram showed dextrocardia with right axis deviation.

\section{CONCLUSION}

Situs inversus totalis with dextrocardia being a rare clinical entity should be interrogated with routing imaging modalities like chest $\mathrm{x}$-ray, transabdominal ultrasound, computed tomography and barium studies to make the patient and clinician aware of this condition, thereby preventing wrong diagnosis and surgical mishaps.

\section{KEYWORDS}

Dextrocardia; Situs Inversus Totalis; Transabdominal Ultrasound; Chest X-Ray; Computed Tomography.

HOW TO CITE THIS ARTICLE: Mandal AK, Bhowmik A. Role of routine screening imaging modalities in the diagnosis of situs inversus totalis- our experience. J. Evolution Med. Dent. Sci. 2017;6 (42):3328-3331, DOI: 10.14260/Jemds/2017/721

\section{BACKGROUND \\ Situs inversus is a term used to describe the inverted position of thoracic and abdominal organs. It is derived from the Latin word "situs inversus viscerum." It is called situs inversus totalis when there is mirror image of abdominal and thoracic viscera. $(1,2,3,4)$ The other types of situs includes situs solitus and situs ambiguous. $(5,6)$ Dextrocardia is defined as the positioning of the heart, mainly to the right with its apex pointing to the right and is seen associated with situs inversus totalis. This condition is rare with incidence of one in ten thousand.(7) It is often detected incidentally during routine screening of the patients with conventional radiography of chest and ultrasound of whole abdomen for unrelated complaints. However, whenever such cases are encountered they should be reported for the knowledge of treating physician. Moreover, the information should be communicated to the surgeons in case the patient undergoes

Financial or Other, Competing Interest: None.

Submission 17-04-2017, Peer Review 11-05-2017,

Acceptance 18-05-2017, Published 25-05-2017.

Corresponding Author:

Ashok Kumar Mandal,

Department of Radiodiagnosis,

Patna Medical College and Hospital.

Patna-800004, Bihar, India.

E-mail: akmandal.pmch@gmail.com

DOI: $10.14260 /$ jemds $/ 2017 / 721$

\section{MATERIALS AND METHODS}

Our study is a retrospective observational study. We have encountered and included 45 cases of dextrocardia in a time period of 5 years from March 2012 to February 2017 diagnosed with chest $\mathrm{x}$-ray. All of these patients underwent transabdominal ultrasound. Contrast enhanced Computed Tomography (CT), Barium studies and electrocardiogram (ECG) were performed where clinically indicated. We assessed the results of these diagnostic modalities.

\section{Statistical Analysis}

Microsoft Office 2010 was used for statistical analysis. Percentages were used to interpret the data.

\section{RESULTS}

Among 45 patients encountered, 31 were male $(68.88 \%)$ and 14 were female $(31.12 \%)$. The age of the patients ranges from 15 to 65 yrs.

Chest $\mathrm{x}$-ray showed the heart shadow on the right side of the body with apex turned towards right (Fig. 1).

On transabdominal ultrasound, all the patients $(100 \%)$ showed mirror image or complete inversion of abdominal viscera. For example, they had left-sided liver (Fig. 2) gall bladder and right-sided spleen and stomach, (Fig. 3) reversal of orientation of pancreas and transposition of abdominal 
vasculature like superior mesenteric vein and artery, (Fig. 4) portal vein, aorta and Inferior Vena Cava (IVC). Cardiac apex was directed to the right side (Fig. 5).

Computed Tomography (CT) chest and abdomen were performed in $15(33.33 \%)$ of the patients that revealed transposition of abdominal viscera with liver and gall bladder on left side and stomach and spleen on right side. Heart was seen on right side with ascending aorta on left and descending aorta on right side (Fig. 6). Barium meal follow through was done in $9(20 \%)$ patients presenting with pain abdomen and all of them showed right-sided stomach with inverted orientation of small bowel loops (Fig. 7).

CT scan of a 36-year-old male patient who reported with colicky right flank pain radiating from loin to groin revealed radiodense calculus of size $8 \mathrm{~mm}$ seen in the midpole of right kidney with no evidence of hydronephrosis (Fig. 8). Another patient with left-sided flank pain showed a calculus in left upper ureter with mild upstream hydroureteronephrosis. Transabdominal ultrasound findings were consistent with the CT findings in these two patients.

One of the female patient aged 57 years came with vaginal bleeding and on ultrasound interrogation of lower abdomen a diagnosis of cervical mass was made that proved to be squamous cell carcinoma in Pap smear (Fig. 9).

In another 4 patients who underwent CT, distension of small and large bowel loops was seen with multiple air fluid levels and diagnosis of subacute intestinal obstruction was made.

Electrocardiogram (ECG) was performed in 26 (57.78\%) of the patients and all (100\%) were reported of having dextrocardia with right axis deviation (Fig. 10).

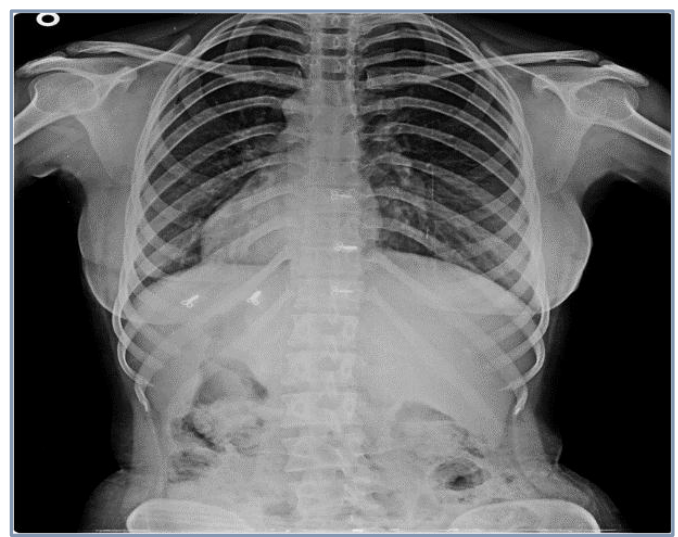

Figure 1. Chest X-Ray showing Dextrocardia (Straight Arrow) and Right-Sided Gastric Bubble (Curved Arrow)

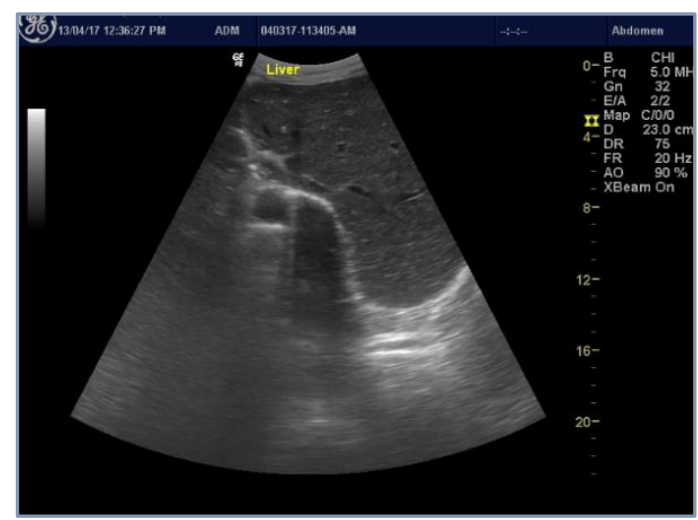

Figure 2. Transabdominal Ultrasound showing Left-Sided Liver

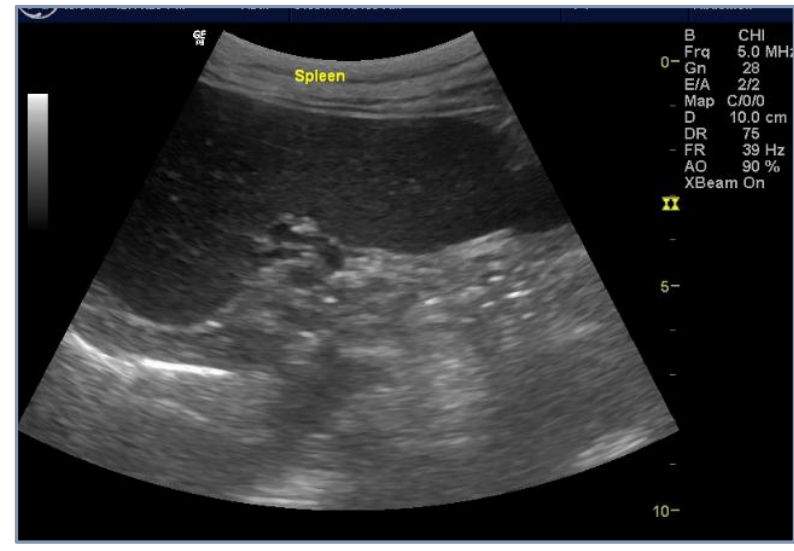

Figure 3. Transabdominal Ultrasound showing Right-Sided Spleen

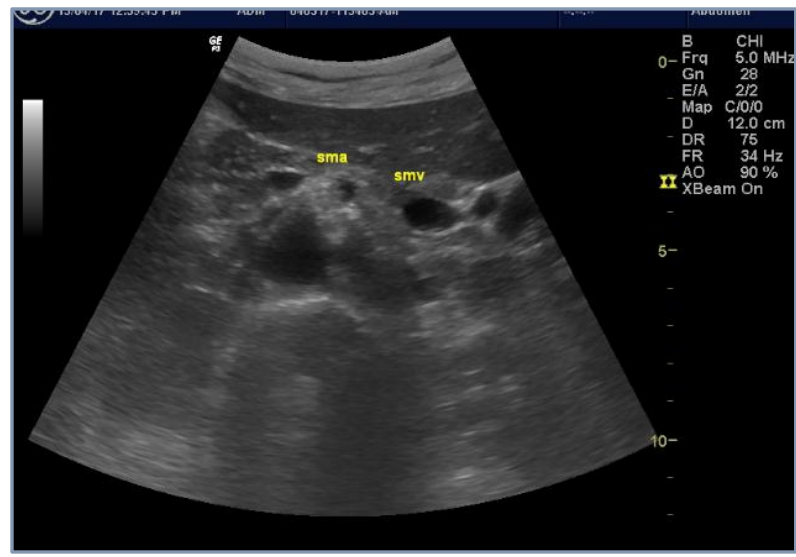

Figure 4. Transabdominal Ultrasound show Transposition of Superior Mesenteric Artery (SMA) and Superior Mesenteric Vein (SMV)

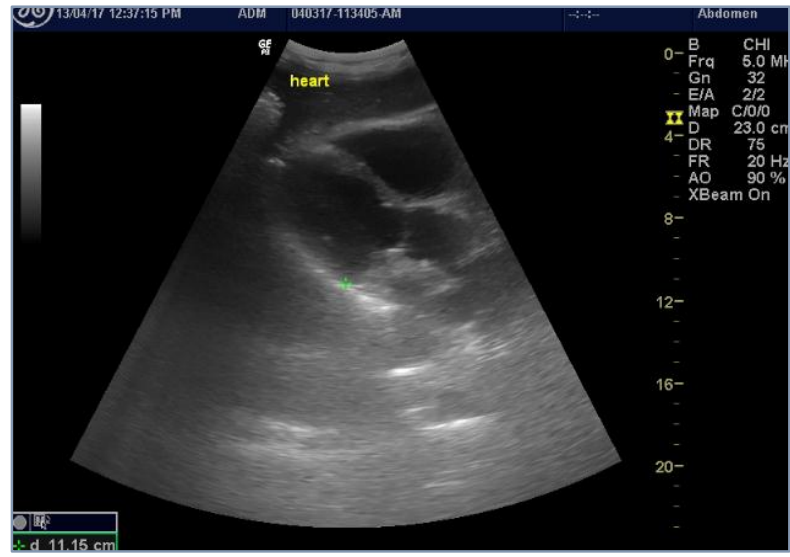

Figure 5. Transabdominal Ultrasound showing Right-Sided Directed Cardiac Apex 


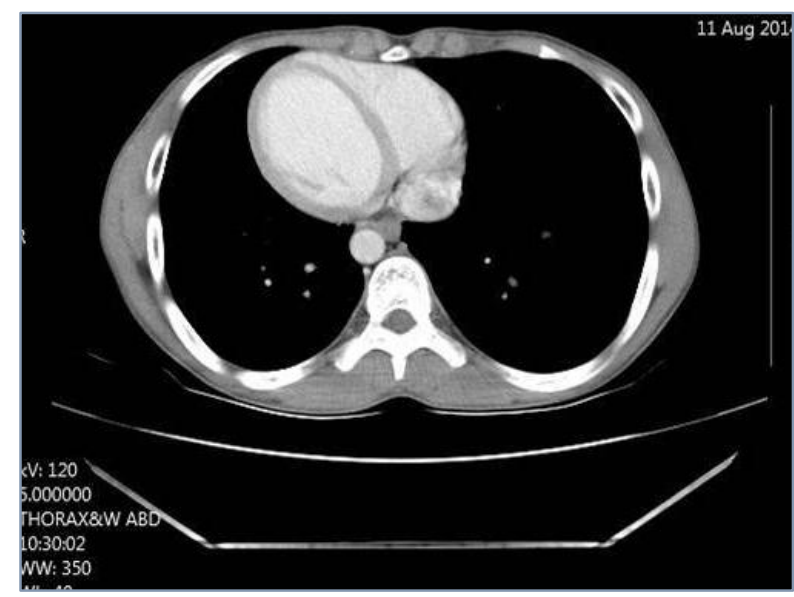

Figure 6. CECT shows Dextrocardia (Straight Arrow) with Right-Sided Descending Aorta (Curved Arrow)

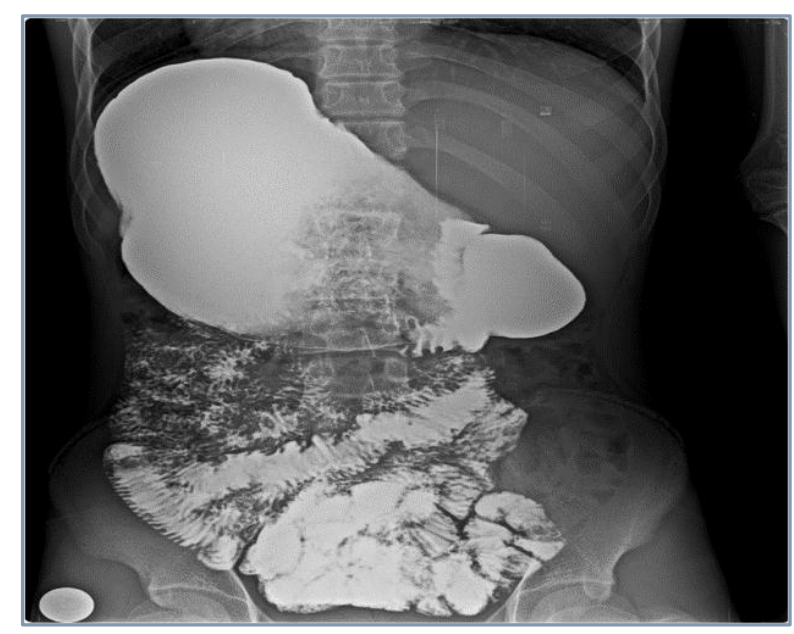

Figure 7. Barium Study revealed Right-Sided Stomach (Straight Arrow) and Abnormal Pyloroduodenal (Curved Arrow) and Duodenojejunal Position

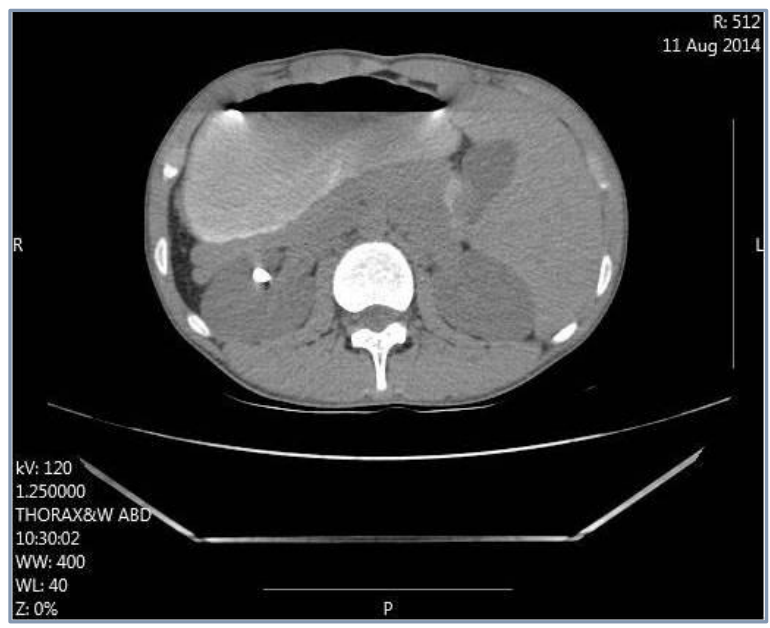

Figure 8. NCCT shows Right-Sided Nephrolithiasis with Situs Inversus

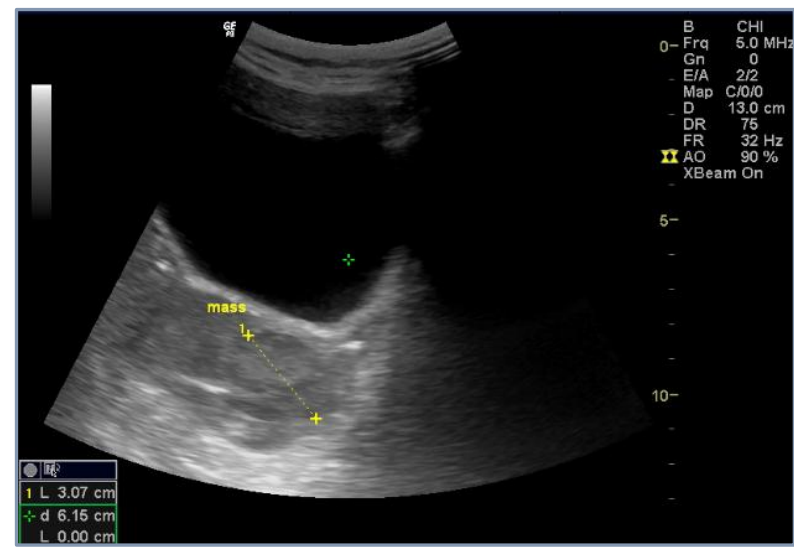

Figure 9. Transabdominal Ultrasound showing Hypoechoic Soft Tissue Lesion involving Upper Endocervix

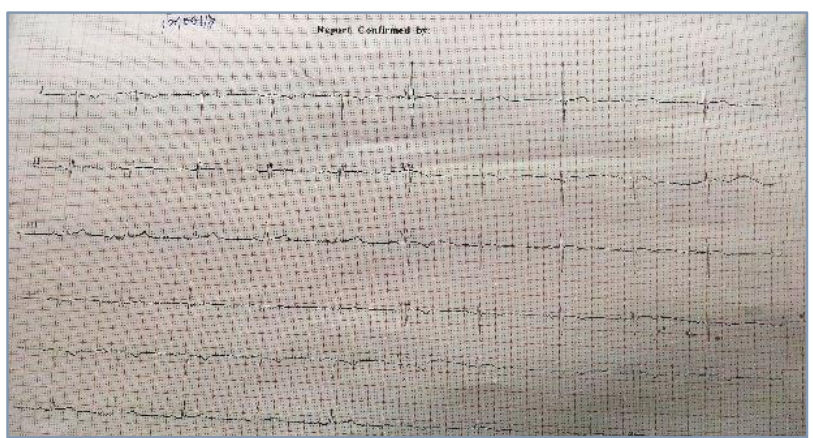

Figure 10. ECG shows Dextrocardia with Right Axis Deviation

\section{DISCUSSION}

Dextrocardia is defined as positioning of the heart mainly on the right with its apex pointing to the right. Isolated dextrocardia usually displays situs solitus (Stomach on left and liver on right). The extent of right rotation of heart in isolated dextrocardia is less than a mirror-image dextrocardia, which is situs inversus. ${ }^{(8)}$

Situs are of three types: Situs solitus (Normal), Situs inversus (Mirror image of normal) and Situs ambiguous. Situs applies to the pattern and morphology of the viscera as a whole and to each asymmetric viscus itself such as the lung, liver, spleen and gastrointestinal tract. It also applies to the heart as a whole and to each of the cardiac chambers, because each is asymmetric.

In situs solitus the right lung has three lobes and an eparterial bronchus, whereas the left lung has two lobes with hyparterial bronchus. The larger lobe of the liver is on the right, and the stomach and spleen are on the left. The morphologic left atrium is to the left of the morphologic right atrium. With situs inversus, the left lung has three lobes with an eparterial bronchus and the right lung has two lobes with hyparterial bronchus, the larger lobe of the liver is on the left, the stomach and spleen are on the right side of the body. The heart is rotated towards the right called as dextrocardia. The morphologic left atrium is to the right of the morphologic right atrium. With situs solitus and situs inversus, the atrial situs always corresponds to the visceral situs.(5)

Situs inversus with dextrocardia is rare with incidence of one in ten thousand.(7) Incidence of congenital heart disease associated with it is $3 \%-5 \%$, the most common being transposition of the great vessels.(6) 
Of these patients, right-sided aortic arch is seen in $80 \%$ cases. The incidence of situs inversus with levocardia is much rarer $(0.00005 \%)$. Congenital heart disease is found in $95 \%$ of these patients. ${ }^{(9)}$

However, surgeons, radiologists and general practitioners should be aware of this condition, as it may lead to wrong diagnosis and surgical mishaps. It also complicates organ transplantation.

Routine premedical examination including transabdominal ultrasound scan, chest x-ray, CT, barium studies and ECG should be encouraged so that patients becomes aware of their condition.

Most of the patients in our experience were imaged for unrelated signs and symptoms like chest pain, abdominal distension, flank pain, bleeding per vaginum, etc.

Dextrocardia detected on routine chest $x$-ray in 45 patients were followed up with routine transabdominal ultrasound in all cases, which confirmed the presence of situs inversus totalis. CT, barium studies reinforced the diagnosis. Right axis deviation with dextrocardia was reported in 26 cases, who underwent electrocardiogram.

\section{CONCLUSION}

Situs inversus totalis with dextrocardia is a very rare clinical entity having an incidence of 1 in 10000 . This condition should be interrogated with routine imaging modalities like chest $\mathrm{x}$ ray, transabdominal ultrasound, computed tomography and barium meal to make the patient and clinician aware of this condition, thereby preventing wrong diagnosis and surgical misadventures.

\section{REFERENCES}

[1] Kosaki R, Gebbia M, Kosaki K, et al. Left-right axis malformations associated with mutations in ACVR2B, the gene for human activin receptor type IIB. Am J Med Genet 1999;82(1):70-6.

[2] Ryan AK, Blumberg B, Rodriguez-Esteban C, et al. Pitx2 determines left-right asymmetry of internal organs in vertebrates. Nature 1998;394:545-51.

[3] Piedra ME, Icardo JM, Albajar M, et al. Pitx2 participates in the late phase of the pathway controlling left-right asymmetry. Cell 1998;94(3): 319-24.

[4] Heymer J, Kuehn M, Rüther U. The expression pattern of nodal and lefty in the mouse mutant Ft suggests a function in the establishment of handedness. Mech Dev 1997;66(1-2):5-11.

[5] Praagh VR. The importance of segmental situs in the diagnosis of congenital heart disease. Semin Roentgenol 1985;20(3):254-71.

[6] Maldjian PD, Saric M. Approach to dextrocardia in adults: review. AJR Am J Roentgenol 2007;188(6): S3949.

[7] Marta MJ, Falcao LM, Saavedra JA, et al. Revista portuguesa de cardiologia: orgao oficial da sociedade portuguesa de cardiologia $=$ Portuguese journal of cardiology: an official journal of the Portuguese society of cardiology. ResearchGate 2003;22(1):91-104.

[8] Jain VV, Gupta OP, Jain J. A rare case of situs inversus with dextrocardia, lutembacher syndrome, and pericardial effusion. Heart Views 2011;12(3):107-11.

[9] McMillan JA, DeAngelis CD, Feigin RD, et al. Oski's pediatrics: principles and practice. Philadelphia: Lippincott Williams \& Wilkins 1999. 